\title{
Occupational Exposure to Vibration and Ischemic Heart Disease
}

\author{
Luciana-Daniela TAMAIAN $^{1}$ and Aristotel CoCARLA ${ }^{2}$ \\ ${ }^{1}$ Pneumoconiosis Lab., Mining Institute, Cluj-Napoca and ${ }^{2}$ University of Medicine and Pharmacy Cluj- \\ Napoca, Department of Occupational Medicine
}

\begin{abstract}
Occupational Exposure to Vibration and Ischemic Heart Disease: Luciana-Daniela Tamalan, et al. Pneumoconiosis Lab., Mining Institute, ClujNapoca-150 miners working in an ore mining area were investigated to evaluate the prevalence of ischemic heart disease. They were assigned to three groups: 50 subjects exposed to vibration with signs of Raynaud phenomenon, 50 with similar exposure without Raynaud phenomenon, and the other 50 , who were not exposed, representing the control group. The three groups were matched in terms of age, food habits, and hereditary risk factors for ischemic heart disease, smoking habits, lipemia, and blood cholesterol levels. In the group exposed to vibration, the prevalence of ischemic heart disease was $11 \%$ and in controls $6 \%(p=0.35)$. The presence or absence of Raynaud phenomenon did not significantly influence the prevalence of ischemic heart disease in the group of subjects exposed to vibration.
\end{abstract}

(J Occup Health 1998:40:73-76)

Key words: Raynaud phenomenon, Ischemic heart disease, Vibration and Ischemic heart disease

In countries in a social and economic transitional period, a large number of workers are exposed to vibration. Under conditions of insufficient protection, the impact on the health status can be considerable.

The variety of functional disorders and clinical manifestations caused by vibration with frequencies ranging between 20 and $200 \mathrm{~Hz}$, outlines the state of vibration disease ${ }^{1)}$, of which neurovascular syndrome is a characteristic manifestation. In addition to peripheral circulation disorders, well known as a result of many studies, a series of other clinicfunctional disorders of the cardiovascular system may occur ${ }^{2}$. It has been proven in a few studies

Received March 28, 1997; Accepted Aug 12, 1997

Correspondence to: L.-D. Tamaian. Pneumoconiosis Lab. Mining Institute, Cluj-Napaca, Str. Cipariu nr. 11, Bl. Bl, Et. 4 Ap. 7, 3400-Cluj-Napoca, Romania dealing with this problem ${ }^{3)}$ that exposure to vibration is related to a higher rate of ischemic heart disease. Thus, Tsvetkov and Tsacheva ${ }^{4)}$ have been related considerably high hypertension disease and ischemic heart disease incidences in vibrationrelated professions. Idzior-Wallus ${ }^{5)}$ also have been shown that vibration and noise may be factors which increase the risk of coronary heart disease. This paper aims at evaluating the prevalence of ischemic heart disease in a group of young miners exposed to vibration with a frequency spectrum between 20 and $200 \mathrm{~Hz}$.

\section{Methods}

The study included 150 miners working in an ore mining area from the north of Romania. All of them come from a geographical area around the mine basin, with identical climatic conditions and food habits. Of these, 50 subjects were exposed to vibration and showed signs of Raynaud phenomenon-group A; 50 were exposed to vibration, but did not show Raynaud phenomenon-group B; 50 subjects included in group $\mathrm{C}$ (control group) were not exposed to vibration as they performed maintenance duties in the galleries.

Vibration are produced by the pneumatic drill $\mathrm{T}$ 90 with a frequency of 30 percussions per second and the miners are usually exposed for 2-6 hr per shift in a cold and wet climate, without any individual protection. The noise level was $96-98 \mathrm{~dB}$, exceeding by 1.06 and 1.08 respectively the permissible levels, and the vibration level was $150 \mathrm{~m} / \mathrm{s}^{2}-100$ $\mathrm{m} / \mathrm{s}^{2}$ respectively, in the frequency band $31.5-125$ $\mathrm{Hz}$, exceeding by 8.3 and 5.5 times respectively the permissible levels. Data were collected on the basis of a questionnaire in which the following were mentioned : duration of professional activity (years), heredo-collateral history of ischemic heart disease, smoking habits and presence or absence of psychological stress related to the profession. Raynaud phenomenon was evaluated on the basis of 
history, physical examination, skin thermometry and cold test. In each of the 150 workers, a lipid concentration was dosed by the Kunkel method, plasma cholesterol by the Watson method (both methods reported by Manta et $\left.a l^{6}{ }^{6}\right)$ and electrocardiograph tracing was recorded. After 5 min rest, while the heart rate became stable, an electrocardiograph was performed. We selected the subjects which described typical effort pain associated with EKG repose modifications : horizonatal or descendent depression of the ST segment, at least $1 \mathrm{~mm}$ at $0.08 \mathrm{sec}$ from the $\mathrm{J}$ point and/or symmetrical negative $T$ wave in at least two adjacent derivations. The clinical diagnosis could not be confirmed by an effort test or/and coronarography, because we did not have the properly medical equipment in the workplace ${ }^{7}$. The relationships expressed as prevalence were examined by the $\chi^{2}$ test and differences between means by the Student's t-test.

\section{Results}

Table 1 shows the main characteristic elements of the three groups of miners. The differences in age and duration of exposure to vibration are statistically insignificant $(p>0.10)$, which emphasizes the homogeneity and comparability of the three groups. Total lipids and cholesterol were within the limits considered normal for our geographical zone and the differences between groups are statistically insignificant. Individually, the higher normal limit was found to be slightly excessive in $15 \%$ in group A subjects, $10 \%$ in group B and $12 \%$ in group $\mathrm{C}$, but these frequency differences are not significant $(\mathrm{A} / \mathrm{B}, \mathrm{p}=0.29 ; \mathrm{A} / \mathrm{C}, \mathrm{p}=$ $0.29 ; \mathrm{B} / \mathrm{C}, \mathrm{p}=0.20$ ). Slight hyperlipemia was found in $14 \%$ of group A subjects, $10 \%$ of group B and $10 \%$ of group $\mathrm{C}$, but these frequency differences did not reach a threshold of significance (A/ $\mathrm{B}, \mathrm{p}=0.29 ; \mathrm{A} / \mathrm{C}, \mathrm{p}=0.29 ; \mathrm{B} / \mathrm{C}, \mathrm{p}=0.20$ ).

These findings are important because the possible frequency differences of ischemic heart disease in the three groups are unlikely to be a consequence of metabolic risk factors. Heredity of ischemic heart disease was reduced and frequency differences were insignificant $(p>0.10): 4 \%$ in group $A, 2 \%$ in group B and $4 \%$ in group $\mathrm{C}$. All subjects reported the same work-related stress factors, including noise, vibration, heavy work, accident risk and the smoking habit, recognized in $36 \%$ of the subjects exposed to vibration and $38 \%$ of the miners in the control group $(p=0.65)$.

Table 1 also shows the prevalence of ischemic heart disease in the three groups: 8,14 and $6 \%$ in groups $\mathrm{A}, \mathrm{B}$ and $\mathrm{C}$ respectively. The prevalence differences were not statistically supported on application of the $\chi^{2}$ test $(\mathrm{A} / \mathrm{C}, \mathrm{p}=0.70 ; \mathrm{B} / \mathrm{C}, \mathrm{p}=0.20)$, but comparing the $\mathrm{A}$ and $\mathrm{B}$ groups together, both exposed to vibration, with the $\mathrm{C}$ group, unexposed to vibration, we found $11 \%$ prevalence of ischemic heart disease in groups $\mathrm{A}$ and $\mathrm{B}$ and $6 \%$ prevalence to group $C$ (control group). In spite of this, the frequency difference does not reach the threshold of statistical significance $(\mathrm{p}=0.35)$.

\section{Discussion}

Functional disorders and morphological lesions of arterial vessels have been found in classical and current studies. Takeuchi et al. ${ }^{8)}$ reported that the prolonged use of vibratory tools produces important morphological arterial obstructive changes as a consequence of vascular wall hypertrophy and subintimal fibrosis. These studies were carried out on finger biopsies in patients exposed to vibration with Raynaud phenomenon. Whether these disorders and lesions remain strictly local or can also manifest themselves at a distance from the area exposed to vibration is a question we cannot answer yet. Tsvetkov et $a l^{9)}$, studying the specific and nonspecific indices for exposure to vibration, created some models which could be used to predict the presence or absence of concomitant diseases, such as hypertension, coronary heart disease and arthritic

Table 1. Mean age, duration of exposure to vibration, total lipids, plasma cholesterol and prevalence of ischemic heart disease in 150 miners

\begin{tabular}{|c|c|c|c|}
\hline \multirow[b]{2}{*}{ Groups } & \multicolumn{2}{|c|}{ Groups exposed to vibration } & \multirow{2}{*}{$\begin{array}{l}\text { Group } \\
\text { unexposed to } \\
\text { vibration } \\
\text { (C) }\end{array}$} \\
\hline & $\begin{array}{l}\text { With Raynaud } \\
\text { phenomenon } \\
\text { (A) }\end{array}$ & $\begin{array}{c}\text { Without } \\
\text { Raynaud } \\
\text { phenomenon } \\
(\mathbf{B})\end{array}$ & \\
\hline Mean age & $45.3 \pm 9.5$ & $47.1 \div 9.0$ & $45.7=9.3$ \\
\hline Duration of activity (yr.) & $15.2 \pm 6.3$ & $14.4 \pm 6.0$ & $16.0=5.3$ \\
\hline Total lipids & $663.2 \pm 110.8$ & $641.2+97.4$ & $614.0-112.2$ \\
\hline Cholesterol & $169.4: 41.5$ & $161.9+42.5$ & $174.6-45.1$ \\
\hline Prevalence of IHD & $8 \%$ & $14 \%$ & $6 \%$ \\
\hline
\end{tabular}


lesions in persons exposed to vibration. In the case of strictly local effects, a higher incidence of ischemic heart disease in workers exposed to vibration could not be confirmed. Over the last 15 years, many observations have supported the existence of more complex mechanisms, which can determine vascular responses on a larger scale. Thus, by their action on peripheral receptors, vibration are considered to disturb the balance of the autonomous nervous system, causing an increase in the sympathetic system tonus, which is a serious disorder in the mechanism of Raynaud phenomenon ${ }^{3,10)}$. This supposition is supported by Hesaki's ${ }^{11)}$ research, which revealed the increase in urinary catecholamines in patients with vibration disease. The increased tonus of the autonomous sympathetic system might be the consequence of a parasympathetic depression ${ }^{3,12,13)}$. According to Matoba et $a l^{14)}$, a series of stress factors, including noise, exposure to cold, vibration, psychological pressure and posture during work, have an effect on the limbic system and cerebral cortex, causing at the same time permanent chronic functional and/or anatomic injuries in the vascular walls. A possible mechanism of small blood vessel deterioration could be an immunological one, as the McHugh's et al. ${ }^{15)}$ studies show. This authors have found a persistent increase in IgG anticardiolipin antibodies in the serum of males exposed to vibration daily at work, and they have considered them to be a marker of endothelial damage associated with vibration-whitefingers. Studying the effect of vibration on the production of hormones and neurotransmitters (ACTH, cortisone, adrenaline, noradrenaline and dopamine), the author provides very convincing arguments for putting vascular disorders within the more general category of responses coordinated by the hypothalamus and the limbic system. Serotonin release is the consequence of platelet aggregation caused by exposure to cold against the injured vascular background, and this has an effect on the 5 HT vessel receptors, triggering vasoconstriction ${ }^{16)}$. Many workers have described abnormal blood rheology in hand arm vibration syndrome including abnormalities of platelet function ${ }^{17)}$, blood viscosity ${ }^{18}$ ) and plasma fibrinogen ${ }^{19}$. Palmer and Moson ${ }^{20}$ ) have shown that the large relative rise in serum Endothelin $_{1-21}$ (a naturally vasoconstrictor produced by the endothelium) may contribute directly or indirectly to vasospasm.

We consider that in the context of these neuroendocrine disorders, which have been currently elicited, this may imply responses on a larger biological level, possibly a vascular involvement of the coronary area. For this, the almost two-fold preva- lence of ischemic heart disease in the miners exposed to vibration compared to the control proup, which is close to the threshold of statistical significance without reaching it, opens a new research prospective. As we know from classical physiology, catecholamines have vasodilating effects on the coronary area and on this basis the problem of ischemic heart disease in vibration disease could be considered as closed. But we should bear in mind that the possible coronary dilating effects, by prolonged action, can produce silent ischemic heart disease in which the coronary arteries are dilated under the influence of vibrations, react by rebound spasms after the interruption of exposure, a phenomenon similar to that known in workers exposed to nitroglycerine in the explosives industry. It is premature to draw conclusions, but our observations suggest that a relation between exposure to vibration and ischemic heart disease unconditioned by the concomitant presence of Raynaud phenomenon is possible. A subsequent study of a larger group of miners could clarify this.

\section{References}

1) Harada N, Matsumoto T. Validity of various function tests performed in Japan as a screening test for vibration syndrome. Int Arch Occup Environ Health $1984 ; 54: 283-293$.

2) Gemne G. Pathophysiology of white fingers in workers using hand-held vibrating tools. Nagoya $J$ of Med Sci 1994; 57 Suppl : 87-97.

3) Heinonen E, Farkkila M. Autonomic neuropathy and vibration exposure in forestry workers. $\mathrm{Br} \mathbf{J}$ Ind Med $1987 ; 44$; 412-416.

4) Tsvetkov D, Tsacheva N. Incidence of hypertension and ischemic heart disease with temporary disability among workers exposed to vibration. Gigiena Truda I Professionalnye Zabolevaniia 1990; (1): 11-14.

5) Idzior-Walus B. Coronary risk factors in men occupationally exposed to vibration and noise. European Heart Journal 1987; 8: 1040-1046.

6) Manta I, Cucuianu M, Benga G, Hodarnau A, eds. Biochemical methods in clinical laboratory. ClujNapoca: Dacia, 1976: 176, 193.

7) Gersh Bj, Bronvalde Rutherford JD. Chronic coronary artery disease. Bronwalde heart disease. W. B. Sounders Comp. 1996; 1289-1366.

8) Takeuchi T, Futatsuka M, Imanishi H, Tamada S. Pathological changes observed in finger biopsy of patients with vibration induced white finger. Scand Work Environ Health 1986; $12: 280$.

9) Tsvetkov D, Boev M, Baykoushev B. Vibrationsdiscriminant models and possibilities for prognosticating specific and nonspecific effects on the organism. Annals of Occupational Hygiene 1992; 36: 253-264.

10) Bovenzi M. Autonomic stimulation and cardiovascu- 
lar reflex activity in the hand-arm vibration syndrome. Kurume Med J 1990; 37: S85-S94.

11) Hesaki $H$. Urinary excretion of adrenaline and noradrenaline in lumberjacks with vibration syndrome. $\mathrm{Br} \mathrm{J}$ of Ind Med 1988; 45: 570-571.

12) Harada $N$, Nakamoto $M$, Kohno $H$, Kondo $H$, Tanaka M. Hormonal responses to cold exposure in subjects with vibration syndrome. Kurume Med J 1990; 37 (suppl) : S45-S52.

13) Farkkila M, Pyykko I, Heinonen E. Vibration stress and the Autonomic Nervous System. Kurume Med J 1990; 37 (suppl) : S53-60.

14) Matoba T, Chiba M, Imitsuba S. Autonomic Nervous System disorders in subjects exposed to handarm vibration. A review of clinical investigation in Japan. In: Gemne G, Taylor W, eds. Hand-arm vibration and the Central Autonomic Nervous System. Proc Intern Symp. London 1983. J Low Freq Noise Vib, 1983 (1 Spec issue) : 74-83.

15) McHugh NJ, Elvins DM, Ring EF. Elevated anticardiolipin antibodies in a patient with vibrationwhite-finger, valvular heart disease and psoriatic arthritis. Clinical Rheumatology 1993; 12: 70-73.
16) Sakakibara $H$, Akamatsu $Y$, Miyao $M$, et al. Correlation between vibration induced white finger and symptoms of upper and lower extremities in Vibration Syndrome. Int Arch Occup Environ Health 1988; 60: 285-289.

17) Ikehata $K$, Kawauki S, Kohno F, Nishiyama $M$, Ide N. Increased platelet function and von Willebrand factor in vibration syndrome. J Exp Med 1980; 27 : 23-28.

18) Okada A, Ariizumi M, Fujinaga $H$. Diagnosis of the vibration syndrome by blood viscosity. In: Brammer AJ, Taylor W, eds. Vibration effects on the hand and arm in industry. New York: John Wiley, 1982: $67-70$.

19) Polanowska R, Cierniewski CS. Activation of blood platelets and increased plasma fibrinogen and fibronection in men exposed to infrasounds, acoustic noise and airborne dust in electric steelworkers. Thromb Res 1987; 48: 363-371.

20) Palmer KT, Mason H. Serum endothelin concentrations in workers exposed to vibration. Occupational and Environmental Medicine 1996; 53 : 118-124. 